\title{
Esclavitud y peonaje: el destierro yaqui en Yucatán, 1900-1912
}

\author{
Slavery and peonage: \\ the Yaqui exile in Yucatan, 1900-1912 \\ Luis Anaya-Merchant ${ }^{1}$
}

\begin{abstract}
Resumen
Este ensayo revisa la cuestión de la esclavitud y el peonaje en Yucatán a propósito del "destierro yaqui". El entreveramiento de estas formas de producción, de tres guerras que cruzan ese destierro, de la relativa cortedad histórica, el carácter sobre politizado de las primeras denuncias y una historiografía dividida no han facilitado aclarar la existencia de dichos fenómenos. Para aclararlos se discuten algunos asertos fundamentales de la historiografía contemporánea sobre el régimen paternalista en las haciendas henequeneras yucatecas durante el Porfiriato tardío.
\end{abstract}

Palabras clave: esclavitud, peonaje, hacienda, henequén,

\begin{abstract}
This essay reviews the question of slavery and peonage in Yucatan on the subject of "Yaqui exile". The intermingling of these forms of production, of three wars that cross that exile, of the relative historical shortage, the over-politicized nature of the first denunciations and a divided historiography have not facilitated clarifying the existence of such phenomena. To clarify them, we discuss some fundamental asserts of contemporary historiography about the paternalistic regime in the Yucatan henequen haciendas during the late Porfirio Diaz.
\end{abstract}

Key words: slavery, peonage, hacienda, henequen.

Tipología: Artículo de investigación

Recibido: $12 / 03 / 2018$

Evaluado: 07/09/2018

Aceptado: 12/09/2018

Disponible en línea: 24/12/2018

Como citar este artículo: Anaya-Merchant, Luis. (2019). Esclavitud y peonaje: el destierro yaqui en Yucatán, $1900-1912$. Jangwa Pana, 18 (1), 87 - 101. Doi: http://dx.doi.org/10.21676/16574923.2680

\footnotetext{
${ }^{1}$ Doctor en Historia. Universidad Autónoma del Estado de Morelos. México. Tel: +152 7773297082 . Correo electrónico: luisanay@ hotmail.com. Orcid ID: 0000-0002-4595-1921
} 


\section{Introducción}

$\mathrm{U}$ na amplia historiografía mexicanista ha dado cuenta de las condiciones de trabajo en las haciendas yucatecas durante la dictadura del general Porfirio Díaz, 1876-1911 (Aguilar, 1985; Spicer, 1994; Joseph y Wells, 1988; Turner, 1985; Padilla, 2011). Un capítulo que suele incorporar esta literatura es la remisión de "trabajadores" yaquis -e incluso coreanospara sostener el auge henequenero. Este artículo analiza la caracterización que dicha literatura ha propuesto para describir las relaciones de producción de la hacienda henequenera. El artículo despliega su análisis incorporando nuevas aportaciones historiográficas y arqueológicas sobre dichos espacios productivos. El ejercicio involucra como telón de fondo un gran problema moral: el exterminio Yaqui. Problema que al asociarse con el "peonaje" en Yucatán agrava los juicios sobre las oligarquías que los encabezaron. En tal asociación resulta pertinente discutir el asunto de la esclavitud. Incluso la discusión parece obligada para esclarecer si resulta o no pertinente para describir la naturaleza de las relaciones de trabajo existentes; lo cual, además, podría también afectar la caracterización del régimen que las prohijaba.

La diáspora yaqui tuvo una causa, mientras que la guerra tuvo varios ciclos. La causa fue la codicia empresarial por las tierras del pueblo yaqui, mientras que los ciclos se corresponden con la guerra emprendida por los clanes progresistas sonorenses en etapas tempranas del siglo XIX y misma que se acusó con el Porfiriato (en las últimas tres décadas de ese siglo) e incluso durante la revolución. En términos de su ciclo largo, como un continuum, se puede enmarcar entre el segundo tercio del siglo XIX y 1940.

En realidad, esta comunicación se enmarca por tres guerras. La primera, con sus ciclos ya descritos, fue la denominada cuestión Yaqui. La segunda fue la "guerra de castas" en Yucatán (con un arco temporal que inicia en 1946-1948 y cuyas secuelas aún subsistían en la última década del XIX) que, entre otros puntos, implicó una creciente demanda de trabajadores foráneos para soportar el éxito del henequén. La tercera fue "la revolución" maderista (1911-1913) pues los llevó de regreso a Sonora, interrumpió unos años la cuestión Yaqui y los alistó en ejércitos revolucionarios.

El artículo da cuenta de circunstancias que enmarcan el destierro del pueblo Yaqui, los ambientes económicos y sociales que los recibieron en la península caribeña y del pronto desenlace de su experiencia debido a acuerdos maderistas con el antiguo régimen. Estos tres puntos se entreveran con las tres guerras antes mencionadas. Para atenderlos avanzamos con la cuestión Yaqui, en segundo lugar, con su arribo, en tercero damos cuenta de las condiciones yucatecas y como último punto discutimos algunos asertos de la historiografía contemporánea sobre esclavitud y paternalismo en las haciendas henequeneras del porfiriato.

\section{La cuestión Yaqui}

El trasfondo de la denominada "cuestión Yaqui" eran las ambiciones de políticos y empresarios por las tierras que, ancestralmente, poseía esa etnia. Tales ambiciones condujeron una guerra que, como cualquier otra, supuso campañas tendientes a justificar el despojo. El leit motiv de la justificación fue civilizar la región y sus habitantes: es decir, colonizarlos; una experiencia que mantiene paralelismos, y también acusadas diferencias, con procesos coetáneos que "caen" en la amplia esfera de "los problemas indígenas" latinoamericanos. En todo caso, hoy se podría decir, modernizarlos; claro, incluyendo inversión extranjera. El proceso se acentuó con la Reforma (1857-1867), esto es, con el triunfo del programa de liberalización de la propiedad eclesiástica y de las comunidades indígenas. La afectación a la iglesia se contuvo en el Porfiriato mientras que la dirigida a los indígenas continuó. Diversas leyes de baldíos $\mathrm{y}$ deslindes de terrenos fomentaron abusos y especulación. "Empresarios" y funcionarios locales alentaron el deslinde de terrenos mal 
formalizados legalmente para despojar de tierras a los Yaquis. El gobierno federal porfirista respaldó la iniciativa de modo radical. Su vehemencia se aclara por el ascenso del sonorense Ramón Corral Verdugo a la vicepresidencia de la república. Ex periodista, ex diputado y empresario desde su natal Álamos, antigua capital de Sonora, Ramón Corral conocía toda suerte de experiencias y leyendas negras de las poblaciones aborígenes. No extraña que cuando fue gobernador, como sus pares, Rafael Izábal y Luis E. Torres (quien como General fue responsable de la Primera Zona Militar, donde transcurría el conflicto), también impulsara el despojo. No obstante que su secuencia fue más complicada se podría indicar que luego de varios años de enfrentamientos, en 1886 los "rebeldes" sufrieron una derrota de relieve, su líder más importante, Cajeme, fue fusilado en abril de 1887. El despojo se intensificó entonces, pues el gobierno rechazó los títulos de propiedad coloniales de la tribu, colocándolos como terrenos nacionales privatizables $(\mathrm{Hu}, 1984$, pp., 111). En todo caso fue aquel triunviro de políticos progresistas -que alternó la gubernatura- el que decidió el destierro.

La guerra para exterminar al pueblo Yaqui se manifestó en números controvertibles. Es plausible que al inicio del porfiriato la tribu tuviera poco más de 20000 miembros. Un par de décadas después el censo del Estado de Sonora de 1900 fijaba en 14051 su número. Si diéramos por bueno ése registro, la etnia tenía 7251 hombres distribuidos mayoritariamente entre los distritos de Hermosillo 2740, Guaymas $2540 \quad$ y Ures 718; desafortunadamente, ninguno de estos municipios arroja información para distinguir, con claridad, el número de niños; tampoco determina el de niñas y con ello el de mujeres (menos aún el de los grupos de edad de ellas, lo que vuelve aún más difícil tener alguna estimación sobre el crecimiento posible de la etnia). Es plausible que el censo tuviera deficiencias importantes, siendo la principal tender a sub registrarlos. Tal conjetura se soporta en al menos tres razones: las deficiencias comunes a los empadronadores de la época, mismas que se ensanchaban por realizarse en el segundo estado más grande del país, porque se aplicaban a una etnia perseguida y que, además de "sub declarar", buscaba refugio en serranías y zonas mal comunicadas y aún mal exploradas. Por otra parte, se podría sostener que, el cálculo no parecía demasiado alejado de la realidad pues las dos décadas anteriores, al intensificar sus campañas de control sobre brotes rebeldes, el gobierno vigilaba la etnia más estrechamente. El control se expresaba, e.g., en una mejor diferenciación de "rebeldes" y "mansos" en vista de impedir su colaboración, o en la vigilancia más atenta de cruces fronterizos, puntos de venta de armas y lugares de trabajo y abasto.

El censo de 1900 estuvo precedido por dos circunstancias que dan cuenta de esa mayor atención. En primer lugar, hubo la formalización de una promesa de paz celebrada en mayo de 1897 y, en segundo, por la reanudación de las hostilidades. Todo indicaba que ninguna parte creía en el pacto firmado; aunque es probable que la tribu la deseara más que el gobierno. Para firmar la paz de "Estación de Ortiz" los Yaquis exigieron la salida de colonos y militares. El gobierno ofreció amnistía, "condiciones excepcionales" y "grandes concesiones". La versión oficialista subrayó las bondades brindadas a la "raza indomable": "buen trato, dinero, tierras, bueyes para la labranza, semillas para la siembra y alimentos; sueldos a los indios que han sido muchas veces considerados como fuerzas auxiliares; excención de toda clase de impuestos; nombramientos de sus Jefes como autoridades de sus pueblos y región" (Troncoso, 1984). Pero el "arreglo" fue ambiguo y la paz no valió ni el papel en el que fue firmada. Para 1899 resurgió la hostilidad abierta y al comenzar 1900, en la escaramuza del cerro de Mazacoba, el ejército federal derrotó a los milicianos rebeldes.

Antes de Mazacoba hubo deportaciones pequeñas, pero en 1900 sumaron más de 1000 personas. La derrota también significó la dispersión Yaqui hacia Arizona, las serranías y el desierto de Altar. ¿Dónde situar a los deportados de 1900, cómo estimar a los "dispersos"? A falta de registros, de mejores informaciones cualitativas y sosteniendo 
plausiblemente la posibilidad de su sub registro, tendremos que aceptar como cifra base, la de 14 mil Yaquis. Sobre esta aproximación gruesa se debieran deducir los 6 - 6,5 mil deportados a Yucatán. No hay duda de que los gobernantes porfirianos sostuvieron -por las razones que fuera- una voluntad de avasallamiento sobre esta población indígena. Aunque, claro, la sostuvieron de un modo velado. En ese cambio de siglo, un escritor oficialista, Francisco B Troncoso, refiere que los funcionarios gubernamentales revisaban las "tres resoluciones en que se ha pensado y no se han puesto en práctica para acabar con la guerra del Yaqui:

1. La guerra de exterminio para todos los que volvieran a levantarse.

2. La translación de toda la tribú, sacándola del Estado y dispersándola en todas las partes del territorio nacional, distantes de Sonora ó

3. La colonización del Yaqui.

A tono con la hipocresía de la campaña Troncoso rechazó la aplicación de las dos primeras "por inhumanas" y la tercera "por acarrear más perjuicios que beneficios”. Quizá porque él no decidía, cuando menos, podía edulcorar las dudas, pero en actos tangibles el stablishment adelantaba sus tres "resoluciones". Habría que decir una última palabra sobre otra fuente de discrepancias numéricas, ésta corresponde con la degradación lingüística del término "Yaqui" que hacía la población de origen español o mestiza de las mesetas centrales pues, para ellos, el referido vocablo tendía a igualar a ésta etnia con otros pueblos originarios como pimas, seris, mayos, etc. Así, aunque las campañas de exterminio y destierro pretendían restringirse a la etnia Yaqui terminaron por afectar a la mayoría de las antiguas poblaciones nativas. El ejército porfiriano nunca aclaró cómo distinguía a los indígenas de tal o cual grupo. Literalmente levantó cualquier persona de apariencia indígena incluyendo trabajadores bien reconocidos por sus empleadores. Hizo tabula rassa y esto se entiende mejor por la estructura de incentivos con la que el gobierno federal premió a sus diligentes ejecutadores ${ }^{2}$. Claro está acusada diligencia les venía tanto de sus responsabilidades como de sus deseos. Las responsabilidades de la tropa se constituían por incumplir deberes o por desobedecer mandatos superiores. Desde luego, cumplirlas les permitía gozar del aplauso de la gente de bien y tener la satisfacción del deber cumplido, mientras que los altos mandos solían tener incentivos adicionales. John K. Turner afirmó que estos ampliaban su interés privado, aunque no hay constancia de que también beneficiaran directamente a la tropa. Al ejecutar órdenes llevaban una comisión: del precio promedio por indígena vendido (que por lo regular oscilaba entre $\$ 60$ y $\$ 65$ pesos) obtenían $\$ 10$. Además, administraban el presupuesto de su traslado a Yucatán y aquí tenían otras oportunidades de ganancia. Es posible que esto introdujera un sobre registro de los Yaquis desterrados en los números que contabilizaba Turner, pues recogía cifras de militares que se pavoneaban de su riqueza recién amasada (aunque ésta tenía más fuentes que el ingreso por el destierro); además de que él, como periodista militante, le interesaba hinchar la gravedad de ese monstruoso tráfico. No obstante, el argumento contrario también parece bueno para su argumentación: dado que posiblemente no exportaban la cantidad que presumían, tendrían más incentivos para alcanzarla, lo que contribuye a aclarar su desinterés por discernir realmente a los Yaquis de entre otros indígenas y mestizos que solían capturar.

Al margen de que puedan discutirse criterios de clasificación grupal (fenotipo, lengua, costumbres, etc.) y de las dificultades para establecerlas en grupos asediados por la guerra, acaso, faltaría indicar que las cifras de los tres distritos mencionados probablemente fueron de calidad aceptable, pues ahí se ubicaban las principales haciendas agrícolas sonorenses y era ahí donde hubo contacto de más largo plazo con los agricultores locales; los vecinos descendientes de españoles que podían diferenciarlos mejor. 
Otro argumento para aceptar la base cercana a 14 mil es porque, dos años después, los distritos señalados -es decir, donde más eran identificados- fueron los focos del descontento Yaqui. En mayo de 1902, la nueva revuelta se explicó por el rechazo a los bajos jornales y al sistema de anticipos de las haciendas. Parecía que las condiciones de trabajo empeoraban. En todo caso, esto converge con la radicalización de las resoluciones mencionadas por Troncoso.

Otro personaje interesado y entendido del asunto era el ministro fiscal sonorense, Alejandro Ainslie, quien ofrece otros detalles que preocupaban a las elites locales de las revueltas: su periodicidad y sus costos. Con estas preocupaciones transmitió su propuesta para resolverlas al poderoso secretario de Hacienda José Yves Limantour:

cada revuelta, si dura un mes, nos trae 12 meses de atraso y desprestigio. Crueles parecerán sin duda las medidas extremas; pero sin que sea indispensable destruir, la expatriación del indio ya que se impone de una manera definitiva. Distribuir esos millares de desgraciados en estados lejanos, es verdaderamente la gran tarea (CDLIV.2a. 1902.17 de julio).

Por lo demás, él calculaba mal pues no agregó las consabidas corruptelas del ejército cuyos logros, solían ser lentos, limitados y cuestionables. Entrecortados por la resistencia sorda de la realidad que vivían hacendados y rancheros pues por la endémica falta de trabajadores ocultaban Yaquis. No era fácil reemplazarlos con otros inmigrantes, por lo que negociaban su libertad o bien, calmados los ánimos, los volvían a aceptar en sus fincas. Claro, el también Director de La Constitución, el periódico oficial del gobierno de Sonora, calló la convicción más íntima de las elites que representaba: el progreso requería apropiarse de los recursos que poseían los Yaqui.

\footnotetext{
${ }^{3}$ El 2 de septiembre de 1911, el diario católico publicó el pacto con los gobernadores Yaquis para dotarlos de tierras. Francisco Madero también gestionaba el retorno de exiliados en Yucatán.
}

\section{El arribo}

Ya vimos que la cifra de deportados más aceptada oscila alrededor de 6000 personas; siendo que la mayoría fue trasladada entre 1900 y 1908. Es decir, al menos fue más de un tercio de la población estimada en 1900. Fue un gran número de personas sobre todo porque desconocemos los que huyeron a Estados Unidos, al desierto o a serranías vecinas. El ensayo de exterminio tampoco se atenúa porque su permanencia en la península fuera breve. Esta estancia les impuso estragos importantes, aunque su liberación iniciara en 1911, con la insurrección rural "pinista", en el centro de la península. El jefe nacional de la revolución, Francisco Madero acordó su retorno con uno de sus más importantes seguidores en Sonora, José María Maytorena, cuya familia era adversaria del triunvirato y poseedora de haciendas en la región yaqui que, además, tenían interés en su regreso para nutrir sus tropas irregulares (El País, 19113); sin embargo, esbozar las complicaciones de su regreso no aclara el número de los retornados que fácilmente se esfuma. Para la etapa previa incluso podemos señalar que el conteo de los deportados no coincidía con los que arribaron, lo que se explica por los que morían en el camino e incluso por las prácticas de sus captores para hinchar sus números. Las diferencias de edades y condiciones de salud también favorecían dicha diferencia: es posible que los enganchadores prefirieran embarcar familias para agilizar trámites y suavizar con promesas falsas el dolor de la diáspora. La mortandad también crecía por mala alimentación, el cansancio de las jornadas que hacían por su propio pie y por enfermedades que golpeaban más a ancianos, mujeres, niños y combatientes debilitados; asunto particularmente doloroso fueron los de infanticidios (Padilla, 2011) ${ }^{4}$.

En 1911 no hubo cotejos claros con los retornados. Pero en esas lagunas tampoco podemos identificar bien si en esa cifra de 6

\footnotetext{
${ }^{4}$ Actitudes que exhaltan la dignidad son bien conocidas en pueblos en situación de conquista; con los que la experiencia yaqui guarda coincidencias relevantes.
} 
000 había más "mansos" que rebeldes; no es claro cómo discernían los "empresarios enganchadores" que los trasladaban. A más de un siglo de distancia parecía, como lo describieron los funcionarios porfirianos, una "solución final" a la cuestión yaqui.

Los yaquis arribaron a la península, cuando el henequén aún estaba en auge. Su éxito fue asunto inédito en la economía mexicana, en 1870 la producción promediaba por debajo de las 50000 pacas y en 1905 superaba las 600 000 ( 1 paca $=350$ libras $)$. Sin embargo, en 1902 los precios alcanzaron su valor máximo (10 centavos de peso por libra) para comenzar a descender hasta tres centavos, lo que traería muchos problemas a hacendados y en particular a los rivales del molinismo. Esta crisis de 1902 suele subvalorarse; pasó rápido y la producción continuó gracias al financiamiento norteamericano, pero los precios del henequén siguieron bajando paulatinamente en convergencia con el vergonzoso acuerdo Molina-McCormick. Al final del XIX, por fusiones empresariales de McCormic se formó la International Harvester Co. (IHC), que monopolizaría la compra de henequén yucateco, para lo que reclutó a Olegario Molina como su representante. El jefe del clan político y económico más poderoso firmó un acuerdo secreto con la IHC el 27 de octubre de 1902 para reducir paulatinamente el precio de la fibra (el acuerdo se reveló el 27 de noviembre de 1921 en la Revista de Yucatán). Los problemas asociados a la caída de ingresos crecieron cuando los dos principales bancos yucatecos entraron en quiebra técnica debido a abusos especulatorios y manejos fraudulentos (Anaya, 2010). En todo caso, con precios estancados del henequén era previsible que las condiciones de vida de los trabajadores en las haciendas empeoraran.

En las haciendas los Yaquis eran dispersados. Esto ocurría por las considerables distancias entre aquéllas, por su propio tamaño (en las grandes vivían más de 2000 personas como

\footnotetext{
${ }^{5}$ Notoriamente el costo social de la crianza debió ser más alto; a la par su probabilidad de sobrevivencia se
}

promedio) $\mathrm{y}$, sobre todo, porque los hacendados tenían presente la experiencia muy reciente de la guerra de castas. No fue diseñada específicamente para controlarlos, pero los hacendados también la aprovecharon para ellos. Mediante ésta reforzaban divisiones familiares, étnicas y culturales de sus trabajadores. La táctica era tan antigua como Roma y de hecho su solicitud de yaquis parecía responder, al menos parcialmente, a este interés. Aún hoy día los visitantes de las bellas haciendas yucatecas pueden percatarse de sus espacios de 'confinamiento especial', cuartos de castigo o cárceles privadas que obviamente servían para disuadir a los descontentos con las labores cotidianas. Recientes trabajos de arqueología histórica del siglo XIX han ido más lejos destacando diferencias de apariencia más sutil entre los pueblos libres $o$ independientes bajo el cobijo rebelde durante la guerra de castas y las haciendas dedicadas a cultivos comerciales (henequén, azúcar, salinas principalmente), en éstas la arquitectura se inclinaba a subrayar la diferenciación tendiente al control social (Meyers, 2014).

Notoriamente las divisiones que imponían los hacendados tenían consecuencias más gravosas sobre los recién llegados. No es claro que la comunicación entre trabajadores fuera fluida y esto podía tener consecuencias devastadoras especialmente para los enfermos, pues padecían además al no hablar maya y, en consecuencia, no tener acceso a plantas o remedios de la medicina local tradicional para curar "enfermedades" o picaduras de insectos en sus viviendas. Esto, no era asunto menor, pues sus nuevas rutinas se caracterizaban por cargas de trabajo excesivas que aunado a la mala dieta los debilitaba, volviéndolos vulnerable a agentes patógenos tropicales ${ }^{5}$.

Por lo demás hay evidencia de que fueron vistos como focos de virulencia. Así ocurrió en la sobrecargada atmósfera económica de 1908. Por si fuera poco, esa primavera se registró un incendio mayúsculo: la hacienda de Temozón

reducía. Infortunadamente no hay elementos suficientes para estimar -aproximadamente- su capacidad reproductiva básica. 
y sus "31 700 mecates de henequén de primera, valuados en más de 400000 pesos, se convirtieron en humo" (Joseph y Wells, 1988, p. 251). Para continuar la mala racha, en marzo, el arribo de 113 deportados coincidió con un brote de viruela. Entonces menudearon los señalamientos contra los yaquis como responsables del virus $\mathrm{y}$, aprovechando el encono y el ambiente preelectoral, también contra el vicepresidente Corral por enviarlos. La última acusación era reveladora: la protesta se dirigía contra el clan científico, que encabezaban Corral y Olegario Molina, ex gobernador y actual Secretario de Fomento ( $E l$ Padre, 1908: 28). Huelga mencionar que este también fue el ambiente en el que se escribiría el libro más conocido sobre la situación yucateca, México bárbaro.

\section{Yucatán o México bárbaro}

Hacia 1900, Yucatán tenía poco más de 300 000 habitantes y muchas interrogantes sobre sus habitantes del pasado. El problemático asunto de la despoblación ha sido discutido por una amplia literatura durante varias décadas. Desde los años 80's, gracias a una mejor comprensión de las lenguas originarias, epigrafistas, historiadores del arte, arqueólogos, geólogos, paleobiólogos y otros profesionales han ofrecido una reinterpretación sobre los patrones de mortandad y dispersión poblacional motivadas por modos de cultivo asociados, claro, a características del suelo de fácil sobreexplotación vinculada también a la excesiva fabricación de estuco, a ciclos de sequías asociados a cambios de orden global y al vulcanismo circundante, etc. (Richardson, 2008).

Al compararse con otros estados que tenían importantes poblaciones indígenas originarias y territorios de extensión semejante se entrevé el déficit. Así Oaxaca, Michoacán o el Estado de México sin estar sobrepoblados contaban promedios que triplicaban a Yucatán, rondando cifras de un millón de personas. Al margen de la base demográfica colonial, resulta plausible que la población yucateca pudo crecer modestamente hasta la guerra de castas. Entre sus estragos deterioró el frágil crecimiento que mostraba antes la población maya. Otro efecto, ya señalado, ocurrió en los patrones de asentamiento de pueblos mayas. Además, nuevos estudios han descubierto la preexistencia de un sistema de agregación y dispersión, que respondía a fenómenos mayores como el colapso de Mayapán o la invasión española, la Independencia, la guerra de castas, etc. Esta guerra produjo bajas poblacionales y tendencias que favorecieron la concentración. También tuvo consecuencias culturales como revitalizar expresiones religiosas populares, quizá el ejemplo más notable fue la veneración de la cruz parlante. Desde luego, aquí nos interesan las de naturaleza profana, como el hecho de que los hacendados yucatecos persiguieran controlar y disciplinar con más énfasis a los trabajadores de sus fincas. Algo que ha dejado huella: una auténtica «arqueológica del peonaje» porfiriano en los espacios productivos del henequén. No obstante, la diversidad entre las haciendas, en cuanto a su extensión, posibilidades económicas de sus propietarios, productos, acceso a mercado, etc., la evidencia arqueológica indica que las haciendas tendieron a reforzar jerarquías internas como método para afrontar la persistencia de grupos armados (Alexander, 2014). Podría, claro, abrirse la cuestión de qué tan extendido fue este fenómeno, si fue más notorio en áreas de conflicto, pero no es menos cierto que aún hoy pueden observarse prisiones privadas y/o espacios -ciertamente reducidos- de confinamiento y castigo que en su época debieron haber sido utilizados, aunque solo fuera como amenaza.

Las condiciones sociales de los trabajadores llamaron la atención durante el auge henequenero. Las primeras informaciones y alegatos fueron locales. Su primer gran escándalo ocurrió en noviembre de 1904 al circular una carta abierta contra Audomaro Molina Solis, hermano de Olegario (el entonces Gobernador), donde se le acusaba de vejar y esclavizar a sus trabajadores. Tomás Pérez Ponce, un conocido abogado meridano y por un periódico opositor, El Padre Clarencio, eran sus acusadores. Gracias a los contactos de su director A. R. Escoffié con los hermanos Flores Magón la noticia del abuso circuló en la 
ciudad de México mediante las páginas de Regeneración, sin duda, el periódico más afamado y el opositor más serio al régimen. La respuesta del stablishment vino por dos flancos, el periodístico y el judicial. Al comienzo de 1905, mientras el oficialismo negaba la esclavitud en Yucatán, Pérez Ponce y Escoffié eran encarcelados. La denuncia escaló con rapidez porque estaba en juego la competencia electoral por la gubernatura y un bando de tinte antirreeleccionista, vinculado a Delio Moreno Cantón, figura relevante de la política local que se oponía a la sucesión dentro del clan Molina. La campaña de la prensa opositora promovía el engrose morenista o, si se prefiere, antirreeleccionista (Joseph y Wells, 1988; Escalante, 2004).

Habría que decir que sirvió plenamente a ese fin cuando, unos años después, el escándalo cobró notoriedad internacional gracias al importante libro México bárbaro de John Kenneth Turner. Con justicia el libro es considerado una de las denuncias más punzantes contra la dictadura porfirista; algo que ésta reconoció y lo llevó a intentar su censura en los EUA. Al difundirse publicación desprestigió al osificado régimen, erosionando su aceptación entre la ciudadanía estadounidense. México bárbaro justificó o, cuando menos, aclaró razones fundamentales del estallido revolucionario que inflamó a México. Luchar contra la esclavitud yucateca era luchar contra Porfirio Díaz.

Por la importancia que guarda la esclavitud como tema central del libro conviene detenernos en mostrar aspectos de su elaboración. Junto a otros compañeros socialistas, Turner formaba parte comités de defensa de refugiados mexicanos en los Estados Unidos. El prestigiado abogado socialista Job Harriman y A. R. Holston serían los representantes legales de los líderes del Partido Liberal Mexicano (PLM), perseguidos por el porfirismo desde hacía años. Cabe resaltar que la suerte del PLM habría sido otra, aún más desafortunada sin el apoyo de los grupos izquierdistas norteamericanos que, desde luego, también padecían acosos y que en la defensa de los radicales mexicanos, deseaban reflejar el internacionalismo de su propia lucha (Bufe y Cowen, 2005). En sus contactos con sus defensores, Ricardo Flores Magón les describió la opresión que vivía México y entre los ejemplos recientes pudo citar el escándalo yucateco, aderezado por la continuada guerra y destierro del pueblo Yaqui a Yucatán. Turner y su esposa Ethel Duffy Turner tendrían noticia de estos y otros casos en la prisión de Los Ángeles. Ahí y en conversaciones con otros militantes que conocían México fue donde Turner decidió viajar a Oaxaca y Yucatán presentándose como un inversionista norteamericano. En septiembre de 1908 comenzó su periplo y reportaría sus experiencias en el American Magazine a lo largo de 1909 y dado su éxito, en 1911 los reportajes serían reunidos y editados como México bárbaro.

El tema central de Turner era el problema que el PLM describió años atrás: el incumplimiento de la ley. Al recordar la conversación con los magonistas, Turner enumeró pruebas de su dicho, como la falta de garantías individuales reflejada en persecución de periodistas independientes, falta de elecciones libres, etc. La falta de garantías individuales alcanzaba nitidez cuando se convertía a trabajadores libres en esclavos.

Quieren decir esclavitud del asalariado, o esclavitud de condiciones de vida miserable. No querrán significar esclavitud humana.

Pero aquellos cuatro mexicanos desterrados insistieron:

-Sí, esclavitud -dijeron-, verdadera esclavitud humana. Hombres y niños comprados y vendidos como mulas, y como tales pertenecen a sus amos: son esclavos. (Turner, 1985, cap. 1)

Inicialmente Turner se sorprendió que subsistiera esclavitud antigua en la república mexicana. En sus observaciones, no hay diferencias sustantivas con respecto a la servidumbre por deudas, aunque ésta adopté la denominación de "servicio forzoso por deudas" que prohijaban los hacendados para hipócritamente rechazar el mote de propietarios de esclavos. O, en sus palabras: "no nos consideramos dueños de nuestros 
obreros; consideramos que ellos están en deuda con nosotros. Y no consideramos que los compramos o los vendemos, sino que transferimos la deuda y al hombre junto con ella" (Turner, 1985, cap. 1). Turner refutó que el servicio por deudas no fuera esclavitud considerando que existía la costumbre "de traspasarse los esclavos... no sobre la base de que los esclavos deben dinero, sino sobre el precio que en esta clase de mercado tiene un hombre". Es claro, al hacer su denuncia meditaba sobre esta diferencia que es del todo relevante. Excavó poco en la declaración de los propios hacendados que explícitamente excluye a sus "obreros" de la posibilidad de contratarse legalmente con algún otro hacendado; a la letra, incuestionablemente, los consideran un objeto transferible. Esto hace claro contraste con los obreros auténticos que, a diferencia de los esclavos, no están excluidos del derecho legal de participar en el mercado laboral de manera libre ${ }^{6}$. Los obreros o esclavos modernos podrían quizá vivir peor que un esclavo, pero legalmente son sujetos de derecho y no objetos que pueden transferirse sin su voluntad a otros dueños de esclavos.

Y, por cierto, Turner llegaba a Yucatán cuando la crisis de 1908 golpeaba a los henequeneros y los productores directos habían bajado de precio a solo $40 \%$ su valor previo a la crisis. Observador atento consideró, claro, que el "servicio por deudas, en forma más moderna que en Yucatán, existe en todo México y se llama peonaje", y precisó líneas adelante:

La esclavitud es el peonaje llevado en último extremo, y la razón de que así exista en Yucatán reside en que, mientras en algunas otras zonas de México una parte de los intereses dominantes se oponen al peonaje $\mathrm{y}$, en consecuencia, ejerce cierta influencia que en la práctica lo modifica, en Yucatán todos los interesados que dominan la situación se dedican a la explotación del henequén, y cuanto más barato es el obrero, mayores son las utilidades para todos. Así el peón se convierte en esclavo (Turner, 1985, cap. 4).

En otras situaciones, como al describir la persecución de "esclavos prófugos" en Valle Nacional, Turner reitera: "la esclavitud no es otra cosa sino peonaje o trabajo por deudas llevado al extremo' (Turner, 1985, cap. 4). El peonaje en su "extremo" o si se prefiere, en su conclusión lógica, es esclavitud. No obstante, el curso predominante de la experiencia histórica europea siguió un sentido contrario; el esclavismo de la antigüedad clásica derivó en formas de servidumbre medievales, en las que parece caer mejor el peonaje. Pero, es claro, la historia no sigue trazos unilineales y es bien sabido que el esclavismo antiguo convivió con formas de trabajo servil. En consecuencia, Valle Nacional y Yucatán apenas presentan diferencias mínimas. Son más notorias las que tienen respecto de 'otras zonas' del país, donde los intereses dominantes -por decirlo así- divergían, aunque no nos aclaró en qué divergían. En todo caso, lo que sí se observaba en la meseta central mexicana era una tendencia a disolver las antiguas economías morales (parroquiales) en las que se habían desenvuelto las relaciones de trabajo entre peones y hacendados.

Por lo demás es cierto, y especialmente en la meseta central, que operaban tendencias a modificar los dictados de la economía moral tradicional. A diferencia de gañanes, menestrales, arrendatarios y comunidades campesinas periféricas, los peones de las haciendas recibían granos a precios menos oscilantes y pagos en especie. Era una vieja costumbre que las haciendas cubrieran saldos monetarios (aunque solo fueran contables) de los peones con raciones de víveres a precios diferentes del mercado abierto. Nickel identificó que, al final del porfiriato, un mayor número de hacendados cuestionaba estas prácticas, enjuiciándolas sesgadamente de "onerosas e ineficientes". Ahora preferían tratar a sus antiguos peones como trabajadores libres. Era una separación paulatina de la vieja

\footnotetext{
${ }^{6}$ Dejamos al margen la polémica que supone definir al mercado de trabajo como un mercado donde intercambian iguales a valores equivalentes.
} 
economía moral que seguía el camino de elevar jornales en relación con la productividad $\mathrm{y}$, en paralelo, eliminar "prestaciones" tradicionales. Por tanto, parecía que los cambios obedecían a reducciones de costos de producción y/o procesos de racionalización capitalista en marcha ${ }^{7}$. Parecía que el resultado era abaratar los costos laborales de esas empresas. Y, en este respecto, realmente Yucatán ¿mostraba una dirección diversa? No lo parecía, sobre todo si recogemos la anterior cita de Turner: 'en Yucatán los intereses dominantes se dedican a producir henequén, y cuanto más barato sea el obrero, mayores serán sus utilidades'. Claro, por contexto, cuando él escribía "obrero" realmente quería decir esclavo, como lo muestra la cita en extenso. Entonces y si a diferencia del obrero, el esclavo debe ser alimentado, aunque descanse, el problema radica en demostrar que los costos de la esclavitud eran menores frente a los del obrero libre en la meseta central, es decir, en espacios donde la producción de alimentos era relativamente más barata que en la península y donde al antiguo peón, ahora trabajador libre, no se le pagaba por los días no trabajados. No creo que esta interrogante contradiga el análisis de Turner y mucho menos que edulcore la situación de peones y esclavos en Yucatán; en todo caso, habrá que indagar en otros sentidos y considerar que el proceso de transformación de la economía moral en la meseta central deterioró más acelerada y profundamente las condiciones de vida de los productores primarios en el altiplano.

\section{Esclavitud, resistencia y paternalismo}

Joseph y Wells han descrito la estructura de dominación de la hacienda henequenera yucateca. Para ellos ésta fue una «institución híbrida»; con el término designan una mezcla y una incompletud transformativa. Es decir, le atribuyen una base original: la hacienda maicera ganadera colonial. El carácter

\footnotetext{
7 Faltan más estudios sobre un empleo mayor del arrendamiento por los hacendados que vieron afectadas sus propiedades y mostraban cautela para reinvertir en sus propiedades.
}

inacabado del cambio ocurre porque, a su juicio, la hacienda henequenera no logró mutar a una industria que utilizara "técnicas nuevas", ni logró diferenciaciones laborales que desplazaran al trabajo simple por otros más especializados, como sucedía en la industria azucarera del Caribe. De la hacienda henequenera no emergió "una sociedad de plantación plenamente desarrollada" debido a los "vestigios" de la hacienda maicera ganadera [que cargaba o la atrasaban] y por "la forma en que los hacendados enfrentaban problemas de mano de obra". Con los "vestigios" parecen referirse al sistema de peonaje que aparece repetido bajo la idea de "problemas de mano de obra". Dicho sistema tuvo en su centro el "acasillamiento" de peones, es decir, funcionaba impidiendo su movilidad por establecer un sistema de deudas con la hacienda que se perpetuaba a través del "crédito" que le concedía la "tienda de raya" al otorgarles alimentos y bebidas embriagantes que descontaba por adelantado de sus jornales. Desde luego, los autores se percatan con claridad de que sus condiciones laborales eran "más pesadas que su antecesora" aunque señalan que "continuó ofreciendo una medida de seguridad a los peones acapillados" (Joseph y Wells, 1988, p. 219) ${ }^{8}$. A diferencia de las plantaciones de caña de azúcar caribeñas, las de henequén demandaban trabajo permanente descartando "los esquemas de empleo temporal de mayor flexibilidad y rendimiento". Siguiendo su argumento parece plausible que esos "esquemas" también estuvieran presentes en la hacienda "antecesora", aunque lo que más debiera interesarnos son las consecuencias de que el ciclo orgánico del henequén fuera inflexible y que las "condiciones laborales fueran más pesadas" respecto de las haciendas cañera y el maicera. Las circunstancias que confluían en la creciente demanda del henequén ( $\mathrm{y}$ la motivación de los propietarios para obtenerlo) eran absolutamente inhumanas: más dureza en los métodos de trabajo, ninguna evolución tecnológica para cosechar la materia prima,

\footnotetext{
8 Al tratar de "seguridad" refieren la "inculcación de obediencia" al patron y claro, también aluden a satisfactores vitales que la hacienda les proveía: agua, protección contra la leva y un mínimo de alimentos que sus pueblos no les garantizaban.
} 
escasez relativa de trabajadores, ausencia de cultura empresarial, problemas para financiarse de los hacendados, etc. Como se observa era toda una atmósfera redondeada por el espíritu eclesiástico pues varios obispos yucatecos santificaron estos valles de lágrimas (Ménendez, 1995), Por supuesto, el interés central de su trabajo fue mostrar "las formas de resistencia" de los peones ante el deterioro de sus condiciones laborales y "sondear la mentalidad del campesino"; sin duda, otros aspectos de peso, aunque también "intangibles". Habrá que decir que, como Ménendez, lo mostraron y que el lector podría colegir que ésas "formas" variaron en todos los grados posibles: partiendo de las "calladas y cotidianas" llegaron al desafío abierto contra mayordomos y patrones, una vez que la revolución se los permitió. Imposible estar en desacuerdo con estos asertos que evidenciaron la 'oculta conciencia' que tenían de su opresión. Habrá que agregar que supieron aprovechar una lucha política que no iniciaron para establecer su propia lucha por sus derechos sociales y económicos.

Las anteriores precisiones pueden derivarse de "la estructura de dominación" que describen. En contraste, lo que deducen no parece del todo consecuente con los resultados más genuinos de su trabajo. Su conclusión evoca aseveraciones más discutibles que aparecen más claras en otros estudiosos, incluso entre quienes documentan con seriedad los tránsitos más oscuros de la hacienda henequenera. Apuntando hacia los últimos registremos primero su síntesis de la "institución híbrida":

En esencia el monocultivo del henequén gestó relaciones sociales que en cierto modo semejaban un proletariado rural (cuadrillas de trabajo rutinario, trabajo a destajo, salario diario y una economía casi de contado) pero, en otros aspectos, seguía encarnando muchas de las características

\footnotetext{
${ }^{9}$ En sentido original proletarii, con muchos hijos o que solo crían hijos. Los desheredados que no poseen tierra; tan pobres que solo contribuían al Estado reproduciéndose. Excluidos del "oficio" castrense, aunque en tiempos de Mario, en la Guerra de Yugurta, aparecen como voluntarios. Por otro lado, la acepción que sugieren tampoco concilia con la marxista pues los
}

de la paternalista hacienda maiceroganadera (Joseph y Wells, 1988, pp. 219221).

Desde luego, llama la atención la disonancia respecto del significado básico presente del término "proletariado" 9 , pues a éste subyacen las nociones de carecer de medios de producción y la de ser una forma de trabajo libre. En contraste -quepa la precisión- con el peonaje y la esclavitud que son, en la terminología social clásica, modalidades de trabajo no-libre: son modalidades de trabajo forzado directo. Siendo una diferencia -entre otras- que en el peonaje y la esclavitud son forzados a trabajar por el hacendado, el señor o el propietario de esclavos; mientras que, para el proletario (que puede trabajar en un medio tecnológicamente atrasado o en uno avanzado) la compulsión procede de su propia necesidad de sobrevivir: le es interna, si no gana un salario no podrá alimentarse. Por lo demás, las dos modalidades antiguas de trabajo forzado convivieron históricamente; más aún y para continuar con el tema de las combinaciones, es sabido que en la antigüedad clásica y en Roma había esclavos que eran rentados por un salario a otros propietarios. Sobre la compulsión externa dan cuenta amplia Joseph y Wells al recordarnos que "los indios [es decir, los peones] solo oyen por la espalda" (Joseph y Wells, 1988, p. 235) ${ }^{10}$. No hay duda de que se trata de forzamiento directo (esclavitud), aunque los capataces se moderaran al flagelarlos o solo eventualmente amenazaran con castigarlos. En la terminología clásica, esclavitud es trabajo forzado directo y esto es lo que había en Yucatán, incluyendo venta de hombres (la esclavitud-mercancía que por cierto no cuestiona el origen de la esclavitud yaqui que, a todas luces, derivaba de conquistas o "soluciones" de guerra; como la de muchos pueblos bárbaros en la Antigüedad clásica) que vivían para trabajar y cuyo trabajo perseguía -principalmente- el beneficio de

\footnotetext{
peones que describen están encadenados a la hacienda en tanto que los modernos proletarii no tendrían esta condición.

10 "El aforismo yucateco... era algo más que simple humor negro. Reflejaba la creencia generalizada entre la clase dominante de que la disciplina debía ser reforzada por el ejemplo riguroso".
} 
quienes se comportaban como sus dueños, pues -necesariamente- estos reservaban parte del producto a alimentarles. Alimentos escasos $\mathrm{y}$ de baja calidad que les cobraban usurariamente y que los sujetaban con más fuerza por crearles deudas nuevas por consumos que nadie en su sano juicio podría calificar como una recompensa justa por su trabajo. Eran solo el mínimo para satisfacer sus condiciones de reproducción naturales.

Es bien sabido que las sociedades esclavistas clásicas, colocaban a ciudadanos que eran deudores morosos en circunstancias de alta vulnerabilidad pues pendía sobre su cabeza la amenaza de transitar a la esclavitud strictu sensu, es decir a pasar a ser parte del peculio de otro ciudadano - aunque fuera un ciudadano relativamente pobre, propietario de pocos esclavos- que, asistido por la justicia, reclamaba legítimamente su deuda. En éste degradante tránsito de status puede ser difícil distinguir si eran siervos por deudas o esclavos por deudas (Crook, 1967, pp. 36 y ss.); claro podría señalarse que en el primer caso sería una distinción operativa o técnica mientras que, en la segunda, la costumbre imbricaría la posibilidad de su legalización. Creo, al margen de que esto implique alegatos adicionales, que sería exagerado decir que las leyes de la esclavización fueron alguna vez transparentes en la antigüedad clásica y también creo que conocieron muchos cambios en el imperio romano. Solón de Atenas abolió legalmente la servidumbre por deudas en 594 A.C., pero ¿quién podría negar que en la Grecia clásica o en el imperio romano estaban ampliamente difundidos estos tipos de servidumbre? Y ¿realmente tenían un status distinto al de los esclavos? ¿No se podían vender, no podían castigarlos sus dueños? Me parece que una respuesta "letrista" podría colocarnos ante el aparente y ya muy viejo procedimiento de negar la esclavitud por la falta de documentación que la evidencie.

Un tanto más ambigua es una afirmación de Padilla sobre el peonaje y la esclavitud. Luego de confirmarnos que revisó una gran cantidad de fuentes nos ofrece una conclusión desconcertante: "las relaciones [de los hacendados] con los peones no eran precisamente de tipo esclavista" (Padilla, 2011, p. 43). El "paternalismo tibio" de Joseph y Wells se calienta, casi a renglón seguido traza una comparación de padres reales con hijos reales que se transforma en alusión a relaciones entre hacendados con trabajadoresniños. La "deshumanización racista" presente en la columna vertebral del texto de Joseph y Wells se vuelve inocua:

Un ex hacendado, por ejemplo, cuenta que aprendió a hablar lengua maya con fluidez desde pequeño, pues jugaba y compartía con los sirvientes que vivían más cerca de la casa principal. El hecho de que los hacendados y sus familias se esforzaran por aprender el idioma de sus empleados, y no a la inversa, es un indicador de cómo se manejaban las relaciones de poder al interior de las fincas (Padilla, 2011, p. 44).

No es claro qué tipo de indicador refiere, pero tengo dudas que considero razonables, para desconfiar de las desinteresadas manifestaciones de apariencia filantrópica autoproclamadas por los terratenientes yucatecos. Y esto, con independencia, de que pueda documentarse fácilmente que los mayas sí aprendían y también se preocupaban por aprender español, y esto dicho al margen de los pocos resultados fehacientes que disponemos en torno a las muy escasas escuelas que existieron en las haciendas henequeneras.

La cuestión de la esclavitud yaqui no solo era un asunto de magnitud; de la cantidad (en sus diversas gradaciones) que aportaba su trabajo al producto total en la hacienda henequenera y que, desde luego, era mucho menor respecto del producto que aportaba el trabajo de las más de ocho decenas de miles de peones mayas y los cada vez más escasos "comuneros" libres. La cuestión de la esclavitud yaqui tenía un aspecto más central o, si se prefiere, estratégico que fue representar el mínimo de los costos laborales que pagaba la explotación henequenera. La vida de esos parias era más desechable, un tanto más barata que la de los peones mayas; si bien los costos de la reproducción de las familias o grupos mayas eran bajos, estos conocían mejor las prácticas de amos, amén de que por pertenecer a redes 
de lealtad locales podían resistir más eficientemente sus abusos. En contraste, los yaquis, deshabituados al trabajo forzado lo resistían de manera más directa o burda. Turner testificó casos de flagelamiento en el escaso tiempo de su visita y los contrastó con la mayor obsecuencia maya.

La esclavitud y el peonaje que caracterizó a la hacienda henequenera no presentan distinciones operativas claras. Más aún, después de 1902, cuando agravaron 'las condiciones de dureza' por causas ajenas a la hacienda, cualquier diferencia desapareció. Al iniciar la decadencia romana, durante el siglo IV d.c., los esclavos-mercancía y los capturados militarmente al servicio de los terratenientes producían menos que el producto combinado de campesinos, campesinos pobres, siervos campesinos y otros tipos de trabajadores libres, sin embargo, Roma continuaba siendo una sociedad esclavista: esto es, el trabajo no libre, en sus distintas modalidades permanecía en el corazón de la economía y la ley romana. Y, además, como en Yucatán, este tipo de relaciones productivas se consideraban naturales e inmutables. Vale la comparación pues si los terratenientes romanos del siglo IV ya no podrían explotar a la mayor parte del universo de los trabajadores ni apropiarse despiadadamente de sus productos como en el pasado; en contraste sus pares yucatecos dieciséis siglos después sí podían hacerlo gozando, además, de plena protección legal y aprobación eclesiástica. Me parece irrefutable que toda la riqueza producida en las haciendas "híbridas" yucatecas provenía del trabajo no libre: mayoritariamente de peones esclavizados y en porción menor de yaquis capturados en Sonora, además del caso no tratado, y también minoritario, de coreanos recién inmigrados. La de los coreanos fue una migración económica forzada por su huir de la guerra ruso-japonesa, en el caso yaqui la violencia fue directa contra ellos para despojarlos y uno de sus corolarios fue su destierro. La oligarquía porfiriana promovió

\footnotetext{
11 Pero su aculturación tuvo restricciones, e.g., no fue común que desposaran extranjeros, solían compartir nostalgias, resentimientos contra Japón o asociarse por
}

contactos en Japón y Corea para facilitar la migración. Contratistas norteamericanos transportaron 1033 coreanos de Chemulgo al Itsmo de Tehuantepec. Este número, similar a las migraciones yaquis mayores, llegó a Puerto Progreso, a veinte kilómetros de Mérida. Un interesante índice de su convivencia fue que aprendieran antes el maya que el español ${ }^{11}$. En ambos casos, los poco filantrópicos hacendados reclamarían de inmediato los "préstamos" que significaba otorgarles bienes perecederos que consideraban compras libres, con lo cual los sujetaban a su dominio, avalado por la ley estatal y tolerado por la federal porfirista pese a contradecirla. Joseph y Wells refieren que el Código Civil estatal y abogados locales refrendaban los avalúos de las deudas de los trabajadores como inventario de la propiedad: es decir, eran un activo. Más aún y en contra de su tesis, citan la voz de la costumbre legal: "En Yucatán no existen cuadrillas libres de peones... La hacienda que no cuenta con personas obligadas por contrato personal... no tiene ningún valor" (Joseph y Wells, 1988, p. 237).

\section{Reflexiones finales}

Los liberal-magonistas y Turner entendieron que los yaquis eran ejemplo de hombres comprados como si fueran bestias de carga. Por cierto, había otros agravantes, la venta procedía de un acto de guerra previo y la sostenía un gobierno que se autodenominaba república de tinte nacionalista. Entendieron que eran esclavos y que, en el terreno de los hechos, la dictadura porfiriana los trataba como tales. La historia muestra que la esclavitud puede tener orígenes muy diversos. A los dos que más señalamos podríamos agregar la crianza, el endeudamiento e incluso la autoventa.

Los hacendados henequeneros recibieron a los yaquis sin haber realizado ninguna adaptación social de la que se guarde alguna memoria. Y esto debiera llamar la atención respecto de las condiciones que ya vivían gran masa de peones

oportunidades de mejoría en otros sitios. Sin añoranza de Yucatán se desplazarían a la ciudad de México y Tijuana. 
con las que inició el auge de la fibra. Debiera llamarla, sobre todo, porque las condiciones favorables de inicio -último tercio del XIXfueron modificadas tanto por diversas crisis $(1893,1902)$, como por la reducción de precios de venta que impuso el monoxomio de la International Harvester Co., en connivencia con el clan molinista, el poder político y económico más importante de la península. También resulta revelador que ningún apologista de Olegario Molina, gobernador de Yucatán y ultimo Secretario de Fomento de Porfirio Díaz, haya sido capaz de demostrar las bondades de su gestión del oro verde (un buen ejemplo lo ofrece Casasús, 1925).

Es pertinente señalar que en el esfuerzo de caracterizar adecuadamente las relaciones laborales de la hacienda henequenera, la historiografía parece sobrecargada por distractores: los problemas morales de esas terribles herencias que fueron la guerra de castas y la cuestión yaqui, las formas de resistencia de los peones mayas, lo brevedad histórica la experiencia yaqui, el carácter episódico de sus arribos, su minoritaria participación en el producto final, las querellas de las elites locales por rivalidades personales y motivos electorales, el autoatribuido paternalismo de los hacendados, la avidez de una clase terrateniente que sin cultura ni experiencia empresarial se sorprendió de un súbito éxito económica que no podía consolidar, etc. Y, sin ánimo de ser exhaustivos, todavía hay más asuntos de interés que han ocupado la atención de los interesados en la economía yucateca; como olvidar que, en 1908, cuando el precio del henequén caía, otros dos escándalos mayores (la crisis de los bancos yucatecos y la entrevista Creelman-Díaz) terminaron por opacar la exigua discusión pública sobre el problema de la esclavitud.

Al margen de que haya sido por aclarar estos puntos o por otras razones, el caso es que el revisionismo historiográfico sobre las relaciones laborales prevalecientes en la hacienda parece haber seguido los parámetros del paternalismo que heredó de los propios terratenientes. A lo más afinó su terminología.
No creo que sea lo adecuado. Al margen de que heredara o no tal o cual rasgo de su antecesora maicero-ganadera o de que en su seno no hubiera una transformación con sentido, la hacienda henequenera funcionó para enriquecer a unas decenas de familias y para reducir a la miseria a casi un centenar de miles de hombres, de los que una proporción tenían cónyuge e hijos. No es fácil definir de qué "proporción" hablamos, pero sí podemos afirmar que influía decisivamente en la determinación de las condiciones de vida de los trabajadores de otras haciendas: cañeras, salineras, maicero ganaderas, etc. Ni qué decir de su influencia sobre los pueblos, donde los niveles de vida solían empeorar; la base y noción misma de paternalismo se erige al comparar niveles de vida entre haciendas y pueblos. Ofreciendo protección contra la leva, agua y una ración pobre de alimentos, la hacienda ofrecía lo que los pueblos no garantizaban. Por lo demás, la leva o reclutamiento forzado del ejército era una política gubernamental ante indígenas rebeldes, la lejanía entre pueblos y fuentes de agua se aclaraba por el desenlace de ésa "guerra de castas" y la expansión del henequén; así, al margen de los arcaicos métodos de cultivo mayas y la dureza del clima, las malas condiciones de vida en los pueblos mayas estaban influidas directamente por las políticas gubernamentales y los dictados de la economía internacional. Como vimos, estas condiciones se asemejaban a las que padecían los yaquis por esas directrices. En éstas traslucía la naturaleza despótica del régimen federal pues revelan consistentemente su incumplimiento de las normas constitucionales, amén del trato de esclavos que dio a yaquis y mayas.

El caso yucateco también es sugerente porque la demanda de trabajo vivo fue lo suficientemente amplia para movilizar familias coreanas. Aunque su presencia era minoritaria introducía diferenciaciones entre los trabajadores de las haciendas y abarataba sus condiciones de reproducción. Por otra parte, aunque recibieron información falaz, no llegaron del todo coaccionados, se movilizaron obligados por motivos bélicos guerra y con voluntad para construirse nuevas 
oportunidades; esta conducta innovante suele caracterizar a migrantes de trayectos largos y disposición para no regresar pronto a sus orígenes. Conducta que parece confirmarse en su traslado, en los años 30's, a la ciudad de México y en los 40's a la pujante Tijuana; en las que formarían colonias relativamente prósperas.

El caso del trabajo ya clásico de John Keneth Turner es sugerente para la investigación histórica. No obstante cuestionamientos importantes le hemos dedicado atención especial y por ello vale otra reflexión; inició como otros reportajes de impacto transgeneracional, se publicaron en la exitosa revista The American Magazine al final de 1909 que se editaron -poco después y sin ocultar sus propósitos propagandísticos- como libro. Abrevó acontecimientos pasados matizados por interpretaciones muy politizadas, pero sus dardos convirtieron esos temas económicos y políticos locales en cuestiones de justicia social nacional. Asunto aparte fue la censura porfiriana y la coyuntura electoral acotaran los efectos del libro que, además, tardaría en traducirse al español. Contribuyó a esta pérdida efectual que el regreso de Turner a México en 1913, irónicamente fuera más sufrido que su primera estancia. Alejado -como otros intelectuales norteamericanos- del anarquismo magonista, encontró una revolución distinta a la que imaginó y en la que deseaba participar; lo hizo a su modo terminando en definiciones personales complicadas (Velázquez, 2002); eran los signos de los tiempos. No obstante circunstancias personales, México bárbaro correría por carril propio, pero faltaría tiempo para que nuevas generaciones de mexicanos buscaran aclararse en sus páginas las causas de la convulsión de 1910.

\section{Referencias}

Aguilar Camín, Héctor (1985). La Frontera nómada. Sonora y la revolución mexicana. México, Siglo XXI,

Alexander, R. T. (2014). "Ralph Roys de Nuevo: la ecología agraria y la base arqueológica para los Títulos de Ebtún", en Kepecs, S. \& R. T. Alexander (coords.) El pueblo maya del siglo XIX. Perspectivas arqueológicas e históricas. México: UNAM, Instituto de Investigaciones Filológicas, Centro de Estudios Mayas.

Anaya Merchant, Luis (2010). "El 'secreto infame' y la crisis perenne. Yucatán, de la modernidad fracasada a los albores de la revolución controlada, 1902-1907', en 2010, Memoria de las revoluciones de México, Primavera (7).

Bufe, Chaz y Mitchel, Cowen (eds.), (2005). Dreams of Freedom. A Ricardo Flores Magón reader. AK Press, Oakland, CA.

Casasús, J. (1925). Biografía del sr Lic Don Olegario Molina Solis. Mérida: s.e.

CEHM-CARSO, CDLIV: Centro de Estudios Históricos de México CARSO, Fondo José Yves Limantour.

Crook, J. A. (1967). Law and life of Rome, 90 B.C.-A.D. 212. New York: Cornell University Press.

Du de Hart, E. (1984) Yaqui resistance and Survival. Madison: University of Wisconsin Press.

El Padre Clarencio, 1908, Época III, año IV, $\mathrm{N}^{\mathrm{o}} 2,28$, "Los obsequios del joven don Ramón. Yaquis a Yucatán”.

El País, 1911, septiembre 2. "Madero pacta con los Yaquis que se sometan al gobierno".

Escalante, F. (2004). "La misa negra de $E l$ Padre Clarencio. Gobierno y prensa satírica en Yucatán, 1903-1909. México: Instituto Mora, Tesis Maestría en Historia Moderna y Contemporánea.

Joseph, G. (1984). From Caste War to Class War: The Historiography of Modern Yucatán (c. 1750 - 1940). North 
Carolina: University of North Carolina at Chapel Hill.

Joseph, G. y A. Wells. (1988). "El monocultivo henequenero y sus contradicciones. Estructura de dominación y formas de resistencia en las haciendas yucatecas a fines del porfiriato", en Siglo XIX. Revista de Historia, julio-diciembre, pp. 215-276.

Ménendez Rodríguez, H. (1995). Iglesia y poder. Proyectos sociales, alianzas políticas y económicas en Yucatán (1857-1917). México: CONACULTA.

Meyers, A. D. (2014). "La arqueología del peonaje porfiriano en la hacienda de Tabi, Yucatán”, en Kepecs, S. \& R. T. Alexander (coords.) El pueblo maya del siglo XIX. Perspectivas arqueológicas e históricas. México: UNAM, Instituto de Investigaciones Filológicas, Centro de Estudios Mayas.

Padilla Ramos, R. (2011). Los irredentos parias. Los yaquis Madero y Pino Suárez en las elecciones de Yucatán, 1911. México: INAH.

Ramírez Zavala, A. (2014). "De todo se han aprovechado esos hombres políticos y revolucionarios": los yaquis durante el proceso de formación del estado posrevolucionario: negociación y cambio cultural, 1920-1940”. México: El Colegio de México. Tesis doctoral.

Richardson, B. G. (2008). Las grandes sequías mayas. Agua, vida y muerte. México: FCE.

Spicer, E. H. (1994). Los Yaquis: historia de una cultura. México: Instituto de Investigaciones Históricas, UNAM.

Troncoso, F. P. (1984). Las guerras contra las tribus yaqui y mayo del estado de Sonora, II vols., México: Secretaría de la Defensa Nacional.

Turner, J. k. (1985). México bárbaro. http://files.colectivomexico.webnode.mx/2000000331c35f1d2f2/México-Bárbaro-(conprefacio)\%5B1\%5D.pdf

Velázquez Estrada, R. (2002). "John Keneth Turner y Venustiano Carranza: una alianza en contra del intervencionismo estadounidense". Signos históricos, núm. 7 , ene-jun. 